\title{
AIP Applied Physics \\ Letters \\ Low temperature growth of highly doped GaAs:Si by atomic layer molecular beam epitaxy
}

\section{J. P. Silveira and F. Briones}

Citation: Appl. Phys. Lett. 65, 573 (1994); doi: 10.1063/1.112299

View online: http://dx.doi.org/10.1063/1.112299

View Table of Contents: http://apl.aip.org/resource/1/APPLAB/v65/i5

Published by the American Institute of Physics.

\section{Related Articles}

Correlation between threading dislocation density and sheet resistance of AIGaN/AIN/GaN heterostructures grown by plasma-assisted molecular beam epitaxy

Appl. Phys. Lett. 100, 262102 (2012)

Interplay between $\mathrm{Sb}$ flux and growth temperature during the formation of $\mathrm{GaSb}$ islands on $\mathrm{GaP}$ J. Appl. Phys. 111, 123506 (2012)

Growth of AIN/SiC/AIN quantum wells on Si(111) by molecular beam epitaxy

Appl. Phys. Lett. 100, 232112 (2012)

Conductivity and structure of ErAs nanoparticles embedded in GaAs pn junctions analyzed via conductive atomic force microscopy

Appl. Phys. Lett. 100, 233117 (2012)

Observation of columnar microstructure in lattice-matched InAIN/GaN grown by plasma assisted molecular beam epitaxy

Appl. Phys. Lett. 100, 232102 (2012)

\section{Additional information on Appl. Phys. Lett.}

Journal Homepage: http://apl.aip.org/

Journal Information: http://apl.aip.org/about/about_the_journal

Top downloads: http://apl.aip.org/features/most_downloaded

Information for Authors: http://apl.aip.org/authors

\section{ADVERTISEMENT}

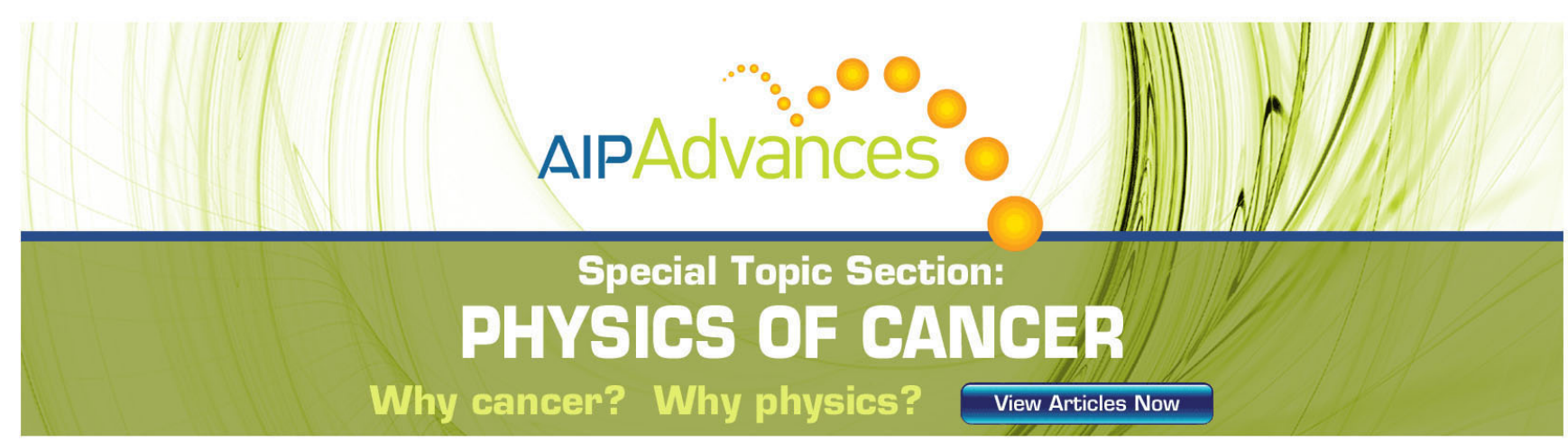




\title{
Low temperature growth of highly doped GaAs:Si by atomic layer molecular beam epitaxy
}

\author{
J. P. Silveira and F. Briones \\ Centro Nacional de Micruelectrónica-CSIC, Serrano, 144-28006 Madrid, Spain
}

(Received 11 April 1994; accepted for publication 16 May 1994)

\begin{abstract}
Two-dimensional growth kinetics characteristic of atomic layer molecular beam epitaxy (ALMBE) allows to extend the range of $\mathrm{GaAs}$ growth conditions to low temperatures while preserving excellent crystallinity and layer morphology. In this work we have used ALMBE technique to obtain GaAs layers highly doped with silicon at substrate temperatures from 200 to $400^{\circ} \mathrm{C}$. At these low growth temperatures donor incorporation is excellent and electron densities of $2 \times 10^{19} \mathrm{~cm}^{-3}$ were reached, limited by the pinning of Fermi level at the $D X$ level. Samples exhibit persistent photoconductivity due to the existence of a $D X$ level resonant with the conduction band.
\end{abstract}

Heavily doped $n$-type GaAs layers have various important applications for high speed electronic and optoelectronic devices or the fabrication of low resistance ohmic contacts.

Silicon has becn used typically as $n$-type dopant for $n^{+}$ $\mathrm{GaAs}$ layers grown by molecular beam epitaxy (MBE). The low diffusion coefficient of silicon makes it attractive for abrupt doping profiles. However, the maximum electron concentration obtained is usually below $5-6 \times 10^{18} \mathrm{~cm}^{-3}$ under standard MBE growth conditions $\left(580-590^{\circ} \mathrm{C}, \phi_{\mathrm{As}} / \phi_{\mathrm{Ga}} \simeq 2\right)$. In fact, due to it's amphoteric character, incorporation of silicon as a donor strongly depends on growth condition. It has been observed that an increase of As/Ga flux ratio during GaAs growth increases the doping efficiency of silicon. ${ }^{\perp} \mathrm{A}$ high ratio $\mathrm{As} / \mathrm{Ga}$ at the growing surface enhances the incorporation of silicon in gallium sites and then consequently the donor density. Higher electron densities can also be obtained by lowering the growth temperaturc. ${ }^{2}$ Carrier concentrations up to $1.8 \times 10^{19} \mathrm{~cm}^{-3}$ in GaAs layers grown at $350^{\circ} \mathrm{C}$ has been reported. ${ }^{3}$ However, these growth conditions are far from the optimum for MBE grown layers being detrimental for the crystal quality. Other studies have shown ${ }^{4}$ that GaAs layers grown at substrate temperature of $200-300^{\circ} \mathrm{C}$ by MBE exhibit very low photoluminescence (PL) signal and very high resistivity.

The development of new growth techniques like atomic layer molecular beam epitaxy (ALMBE) ${ }^{5}$ opens the possibility of growing highly doped samples at low temperatures while preserving a high crystal quality and good surface morphology. ALMBE is a modification of the conventional MBE, based in the cyclic perturbation of the growth front coincident with each monolayer nucleation. This perturbation is induced by pulsing a group $\mathrm{V}$ beam, or by alternating group $\mathrm{V}$ and group III beams. This action produces a variation of surface stoichiometry.

In this study several series of highly Si-doped, 200-nmthick layers were grown on (100) GaAs semi-insulating (undoped and $\mathrm{Cr}$ doped) substrates in a range of substrate temperatures $\left(200-400^{\circ} \mathrm{C}\right)$. After standard oxide desorption at elevated substrate temperature $\left(600^{\circ} \mathrm{C}\right)$, substrate temperature was lowered and $\mathrm{As}_{4}$ cell shut down in order to preserve a $(2 \times 4) \mathrm{GaAs}$ surface reconstruction. Growth rates used in the various samples changed from 0.5 to $1 \mu \mathrm{m} / \mathrm{h}$. Surface morphology was invariably specular with no features observed under Nomarski microscope.

The samples were characterized by Hall effect with van der Pauw configuration. Indium balls deposited as contacts on each corner of a square piece of the sample were annealed just below the temperature of the substrate during growth. Figure 1 shows the measured Hall carrier density as a function of silicon cell temperature. Different symbols correspond to samples grown at different substrate temperatures. For samples grown at $T_{s}=600^{\circ} \mathrm{C}$ we cannot increase the carrier density above $6 \times 10^{18} \mathrm{~cm}^{-3}$, even under high silicon flux. However, this limit is surpassed for samples grown at lower temperatures. Using ALMBE, electron densities can be pushed to $2 \times 10^{19} \mathrm{~cm}^{-3}$ in samples grown at $300^{\circ} \mathrm{C}$, which is to our knowledge the highest value reported. A further increase in silicon flux produces a higher $\mathrm{Si}_{\mathrm{Ga}}$ concentration

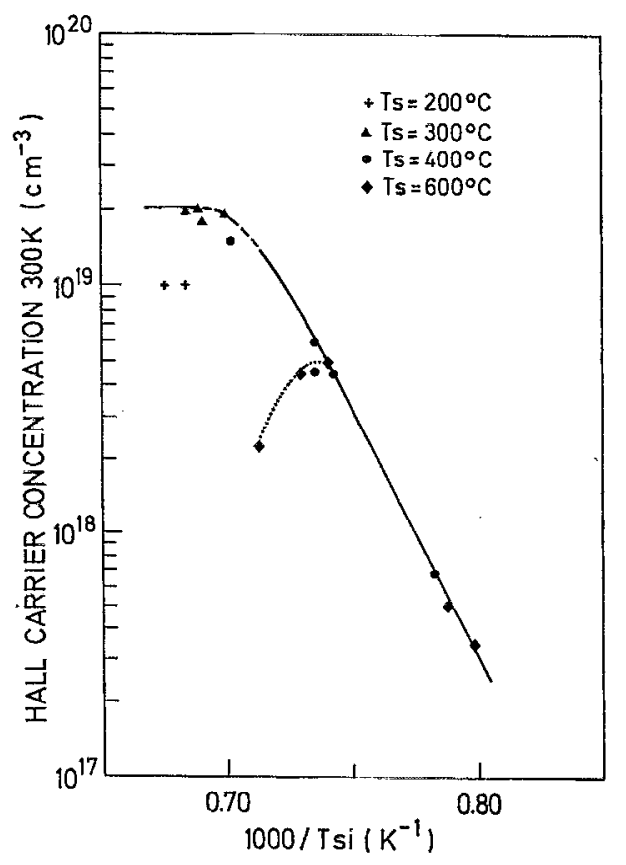

FIG. 1. Hall carrier concentration at room temperature of Si-doped $\mathrm{GaAs}$ as a function of $\mathrm{Si}$ cell temperature. Squares, triangles, and circles represent samples grown by ALMBE at 200,300 , and $400^{\circ} \mathrm{C}$, respectively. Rhombus represent samples grown by $\mathrm{MBE}$ at $600{ }^{\circ} \mathrm{C}$. 


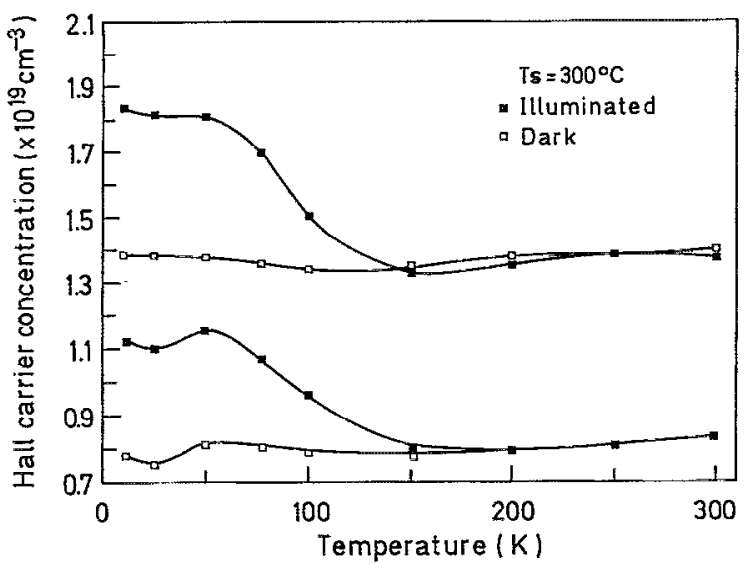

FIG. 2. Hall carrier concentration variation with temperature of Si-doped GaAs layer. Closed and open squares correspond to illuminated and dark measurements.

but not a higher electron concentration as we observed from local vibrational mode measurements. ${ }^{6}$ At lower substrate growth temperatures $\left(T_{s}=200^{\circ} \mathrm{C}\right)$ we observe carrier compensation together with a reduction of carrier mobility. Carrier reduction and compensation might be due to a $\mathrm{Si}_{\mathrm{As}}$ acceptor but it can be originated by other defects also present in low temperature MBE GaAs. ${ }^{\text {? }}$

To get deeper insight into the electrical characteristics of these doped layers, we have performed Hall measurements versus temperature. In some samples with high doping level $\left(5 \times 10^{18}-1 \times 10^{19} \mathrm{~cm}^{-3}\right)$ we observe surprisingly clear persistent photoconductivity effects that in GaAs have been previously observed only under high pressure conditions. ${ }^{8}$ Figure 2 shows, for example, the temperature behavior of samples with a carrier concentration of $1.4 \times 10^{19}$ and $8 \times 10^{18}$ $\mathrm{cm}^{-3}$ at $300 \mathrm{~K}$. Persistent photoconductivity is induced below $150 \mathrm{~K}$ by illumination with a tungsten lamp. Usually, this effect in $\mathrm{AlGaAs}$ or $\mathrm{GaAs}$ under pressure is attributed to an increase of the free carrier density by the photoionizalion of $D X$ centers. ${ }^{y, 10}$

In our case, due to the very high filling of the conduction band achieved, we expect a reduction of the effective barrier for thermal capture into the $D X$ level. A configurational coordinates scheme is shown in Fig. 3 As the carrier concentration is increased, and conduction band fills up the Fermi

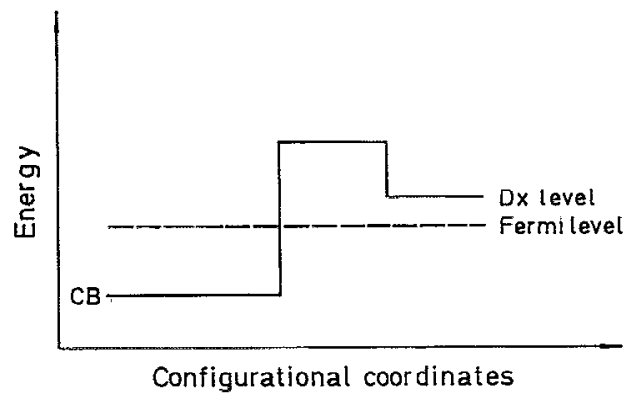

FIG. 3. Schema of the energy levels of conduction band (CB), $D X$ level, and Fermi level in configurational coordinates.

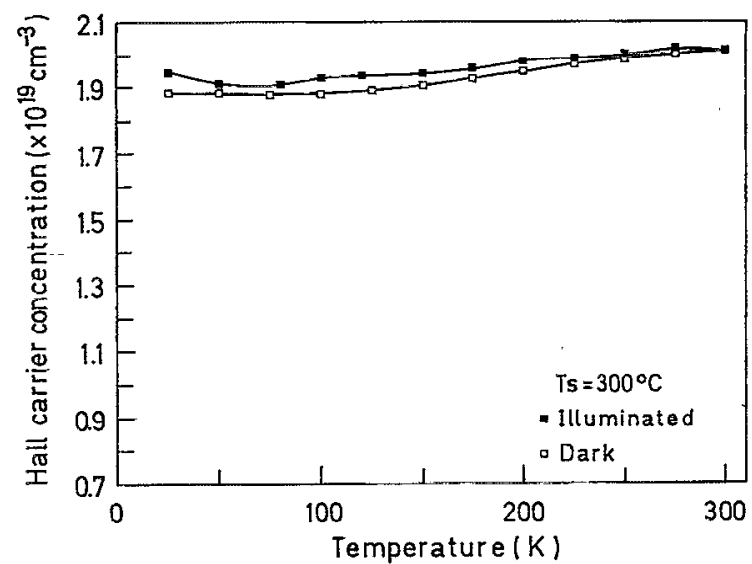

FIG. 4. Hall carrier concentration variation with temperature of Si-doped GaAs layer with limit carrier concentration. Closed and open squares correspond at illuminated and dark measurements.

level moves towards the $D X$ level. Then the maximum observed carrier density of $2 \times 10^{19} \mathrm{~cm}^{-3}$ originates on the Fermi level pinning at the $D X$ level. Therefore, for such doping levels, carrier density will not change with temperature or illumination, as is observed indeed on Fig. 4, corresponding to an electron density of $2 \times 10^{19} \mathrm{~cm}^{-3}$ at $300 \mathrm{~K}$.

To summarize, we have obtained the highest ever reported electron density, $2 \times 10^{19} \mathrm{~cm}^{-3}$ in Si-doped GaAs layers grown by ALMBE at low substrate temperatures $\left(300{ }^{\circ} \mathrm{C}\right)$. Those growth conditions are not detrimental either for crystal quality or surface morphology, and make very attractive the use of extremely highly doped layers as components of optoelectronic devices.

High doping levels achieved allow us for the first time to observe effects of Fermi level well above the bottom of the conduction band in resonance with the $D X$ level. In this way persistent photoconductivity in GaAs without the need of high pressure experiments can be observed. Present experimental work confirms clearly that the $2 \times 10^{19} \mathrm{~cm}^{-3}$ limit is associated neither to the presence of growth effects or silicon solubility limit in GaAs, but to the intrinsic band structure of GaAs.

${ }^{1}$ R. Sacks and H. Shen, Appl. Phys. Lett. 47, 374 (1985).

${ }^{2}$ J. H. Neave, P. J. Dobson, J. J. Harris, P. Dawson; and B. A. Joyce, Appl. Phys. A 32, 195 (1985).

${ }^{3}$ M. Ogawa and T. Baba, Jpn. J. Appl. Phys. 24, L572 (1985).

${ }^{4}$ M. Kaminska, E. R. Weber, Z. Liliental-Weber, R. Lcón, and A. U. Rek, J. Vac. Sci. Technol. B 7, 710 (1989).

${ }^{5}$ F. Briones, L. González, and A. Ruiz, Appl. Phys. A 49, 729 (1989).

${ }^{6}$ M. Ramsteiner, J. Wagner, J. P. Silveira, and F. Briones, Inst. Phys. Conf. Ser. 112, 85 (1990).

${ }^{7}$ M. Kaminska, Z. Liliental-Weber, E. R. Weber, T. George, J. B. Korttight, F. W. Smith, B.-Y. Tsaur, and A. R. Calawa, Appl. Phys. Lett. 54, 1881 (1989).

${ }^{8}$ D. K. Maude, J. C. Portal, R. Murray, T. J. Foster, L. Dmowski, L. Eaves, R. Newman, P. Basmaji, P. Girart, J. J. Harris, and R. B. Beal, "Physics of DX Centre in GaAs Alloys, edited by J. C. Bourgoin (Sci.-Tech., Paris, 1990), p. 123.

${ }^{9}$ T. N. Theis, T. N. Morgan, B. D. Parker, and S. L. Wright, Mater. Sci. Forum 38-41, 1073. (1989).

${ }^{10}$ T. N. Theis, P. M. Mnoney, and S. L. Wright, Phys. Rev. Lett. 60, 361 (1988). 